\title{
Indeks Pengarang
}

A

Achmad Fahruddin Rais 59

Adi Mulsandi 67

Adinda Dara Vahada 91

Alpon Sepriando 79

Asri Rachmawati 91

B

Bony Septian Pandjaitan 91

H

Hartono 79

L

Lutfi Fitriano 67
M

Mamenun 67

$\mathbf{P}$

Pebri Surgiansyah 59

$\mathbf{R}$

Rahmat Hidayat $\quad 67,91$

Retnadi Heru Jatmiko 79

S

Samba Wirahma 91

Sheila Dewi Ayu Kusumaningtyas 47

Soenardi 59

Z

Zubaidi Fanani 59 


\section{Indeks Kata Kunci}

A

AERONET $\quad 47,48,49,50,52,53,55,56,57$ Aerosol Optical Depth 47, 48, 49, 50, 51, 52, 53, 54,55

Angin Permukaan 59, 60, 61, 62, 63, 64, 65

C

CSTm $67,69,70,72,73,74,75,76,77$

Cumulus 91, 92, 93, 95, 96, 97, 99, 100, 101, 102

D

Daytime Microphysics RGB 91, 92, 93, 94, 96, 97, 100, 102

E

ERA5 59, 60, 61, 62, 63, 64, 65

$\mathbf{F}$

Faktor Pertumbuhan Awan $67,70,75,76$
H

Himawari-8 79, 80, 81, 82, 83, 84, 86, 87, 88, 89,

$91,92,93,94,96,98,99,100,101,102$

Hotspot 79, 83, 84, 88, 89

Hujan Estimasi $67,70,71$

I

Indonesia $47,48,49,50,52,53,55,56,57$

K

Kebakaran 79, 80, 81, 82, 83, 86, 88, 89

Konvergensi $59,60,61,65$

M

Modifikasi Cuaca 91, 92, 95, 101, 102, 103

MODIS $79,80,81,82,83,84,86,87,88,89$

S

Satelit $67,68,69,70,71,72,73,74,75,76,77$

V

VIIRS $79,80,81,83,84,86,87,88,89$ 